\title{
Design of Grid-Connected Photovoltaic System
}

\author{
Naseer Khan1, Muhammad Aamir ${ }^{2}$, Faisal Mehmood ${ }^{3}$, Muhammad Aslam¹, Muhammad Arif ${ }^{3}$ \\ ${ }^{1}$ Department of Electrical Engineering, UET, Peshawar, Pakistan \\ ${ }^{2}$ Department of Electrical Engineering, University of Malaya, Malaya, Malaysia \\ ${ }^{3}$ Department of Electrical Engineering, COMSATS, Abbottabad, Pakistan \\ Email: naseerchd@ciit.net.pk,m_aamir801@hotmail.com, faisalmehmood@ciit.net.pk, \\ engr.aslam@yahoo.com,marif@ciit.net.pk
}

How to cite this paper: Khan, N., Aamir, M., Mehmood, F., Aslam, M. and Arif, M. (2017) Design of Grid-Connected Photovoltaic System. Journal of Power and Energy Engineering, 5, 1-12.

https://doi.org/10.4236/jpee.2017.58001

Received: June 14, 2017

Accepted: July 24, 2017

Published: July 27, 2017

Copyright (c) 2017 by authors and Scientific Research Publishing Inc. This work is licensed under the Creative Commons Attribution International License (CC BY 4.0).

http://creativecommons.org/licenses/by/4.0/

\begin{abstract}
This paper presents a grid connected photovoltaic system (PV) with a proposed high voltage conversion ratio DC-DC converter which steps up the variable low input voltages of photovoltaic module to the required DC link voltage. This voltage is applied to an H-bridge inverter which converts DC voltage into AC voltage and a low pass filter is used to filter the output. By adjusting the duty ratio of switches in DC-DC converter, the magnitude of inverter's output voltage is controlled. The frequency and phase synchronization are ensured by a feedback signal taken from the grid. In this way, inverter is synchronized and connected with the grid to meet the energy demand. The PV system has been designed and simulated.
\end{abstract}

\section{Keywords}

Photovoltaic Systems (PV), High Voltage Gain, DC-DC Converter, PWM, Inverter, Synchronization

\section{Introduction}

The demand of electric power is on rise and is anticipated to increase exponentially in future. Among main sources of energy, thermal sources such as fossil fuels contribute to bulk amount of power generation. But these fuels are expensive due to their bulky demand around the world. Also their reserves are limited and running short. Besides this, their combustion generates pollutants gases which affect the environment in various forms. Due to these factors, the renewable sources of energy are getting attention and the photovoltaic systems (PV) are also becoming more prominent during the last few decades. The photovoltaic module provides a low DC voltage with wide range according to various operat- 
ing conditions [1] [2]. A boost converter is required to step up this low DC voltage to the required DC link voltage. The conventional boost converters cannot offer such a high voltage gain. Even in case of extreme duty ratio, the conversion efficiency is declined due to losses. This also increases the ratings of devices like output diode and other issues such as severe electromagnetic interference and reverse recovery [3]. The quadrature converters also offer a high voltage gain, but these have equal voltage stress across the switch [4] [5]. In particular cases, the line frequency transformer can also be used, but it increases the size and weight of photovoltaic system [6] [7]. The grid-connected photovoltaic systems also need the inverters for power conversion, grid interconnection and control optimization [8] [9]. Pulse width modulation (PWM) voltage source inverters are most commonly used in PV systems to invert DC voltage into AC before feeding to the grid or AC loads. The connection of inverters to the grid specifically is dependent on the control scheme which is adopted by these inverters. Different control schemes have been under research for grid-connected inverters in the past decade [10] [11]. The phase locked loop technique is being the conventional. There are other PLL based grid synchronization techniques like power based PLL, quadrature PLL (QPLL). A PLL based new technique for synchronization with the grid has also been developed in [12].

This paper describes grid-connected photovoltaic system with a proposed high voltage conversion ratio DC-DC converter. This system mainly includes two processing stages: a high voltage conversion ratio converter which converts low DC PV module voltage into the required DC link voltage. The second stage is the inverter which converts it into $\mathrm{AC}$ voltage. A low pass filter is designed to filter the inverter output before it is applied to the grid. The DC-DC converter is capable of maintaining the magnitude of inverter's output voltage and inverter guarantees the phase and frequency synchronization of its output. The proposed system finds applications not only in low power, but can also be extended to some extent to large scale allowing the parallel operation of PV modules.

The grid-connected system is shown in Figure 1 with the main constituents as proposed topology of DC-DC converter, inverter and a low-pass filter. As the PV module normally generates low voltage, so a boost converter is needed to step up this DC voltage to a higher value. This output of DC-DC converter is applied to an $\mathrm{H}$-bridge inverter which has four MOSFET switches $S_{1}$ to $S_{4}$. The discrete pairs of switches $\left(S_{1}, S_{4}\right)$ and $\left(S_{2}, S_{3}\right)$ are operated to produce positive and negative half cycles of $\mathrm{AC}$ voltage respectively. For the operation of inverter, the pulse width modulation method is used in which a sinusoidal pulse width modulated signal is achieved by the comparison of a sine wave and saw-tooth wave. This sinusoidal PWM signal is then compared with a square wave to get driving signals for the switches $\left(S_{1}, S_{4}\right)$. Similarly, the sinusoidal PWM signal is compared with inverted square wave to get driving signals for the switches $\left(S_{2}, S_{3}\right)$. The output of inverter comprises of ripples and is filtered out using an LC filter as shown in Figure 1. 


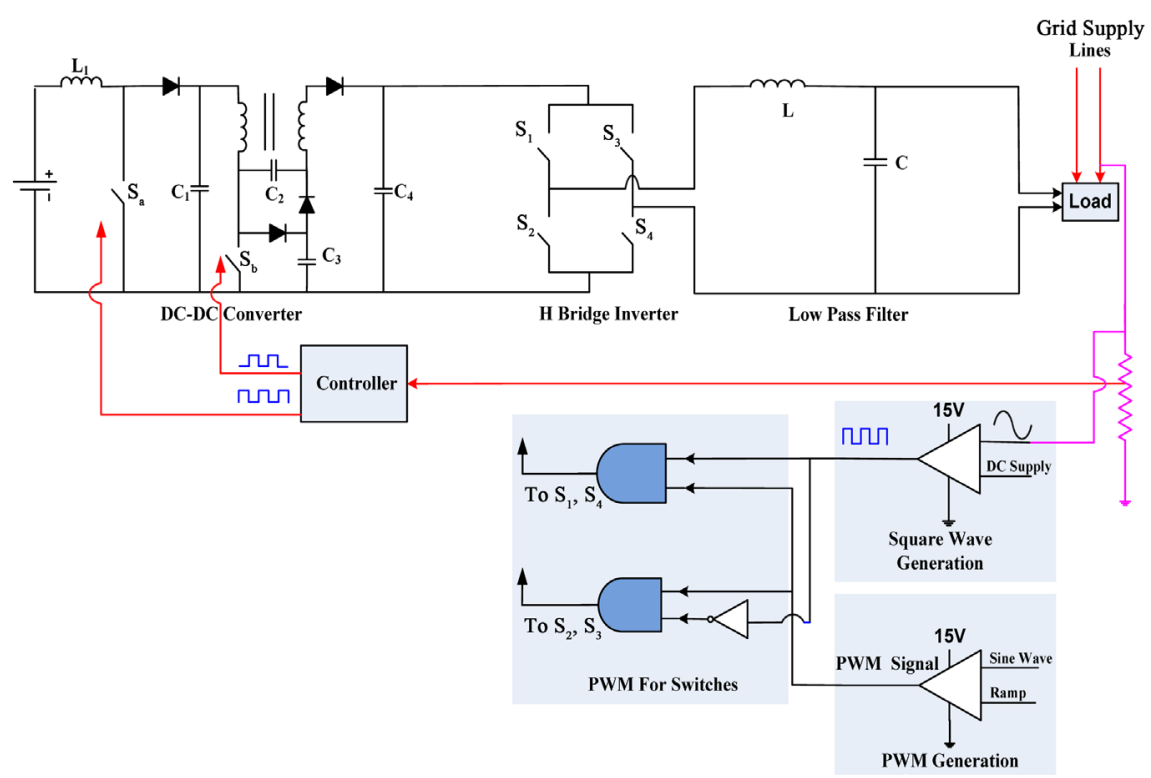

Figure 1. The grid-connected system.

\section{Operation of the Proposed Conveter}

The proposed converter is shown in Figure 2 which includes two stages. An inductor $L_{1}$, capacitor $C_{1}$, switch $S_{\mathrm{a}}$ and diode $D_{1}$ constitute the first stage. A coupled inductor and capacitors $C_{2}, C_{3}$ and $C_{4}$ form the second stage. Switches $S_{a}$ and $S_{b}$ are used to control the operation of first and second stage respectively.

\subsection{Operation of First Stage}

When switch $S_{a}$ is turned on, $L_{1}$ inductor is storing the energy. During this mode, diode $D_{1}$ is reverse biased and capacitor $C_{1}$ supplies current to the second stage which acts as a load. When switch $S_{a}$ is turned off, diode $D_{1}$ becomes on and the current $i_{L}$ flows through the load and capacitor $C_{1}$. These operating modes are shown in Figure 3.

The voltage conversion ratio of first stage is same as boost converter and is given by

$$
\frac{V_{1}}{V_{\text {in }}}=\frac{1}{1-d_{1}}
$$

where $V_{1}, V_{\text {in }}$ and $d_{1}$ are the output voltage, input voltage and duty ratio of first stage respectively.

\subsection{Operation of Second Stage}

Figure 4 shows the second stage of the proposed topology. In order to accomplish mode analysis of second stage converter, coupled inductor is displayed as $L_{m}$ (magnetizing inductance), leakage inductances $L_{k 1}$ and $L_{k 2}$ on the primary and secondary side respectively and a lossless transformer having $n$ as turn ratio. The switch $S_{b}$ controls the operation of this stage. The steady state waveforms of 


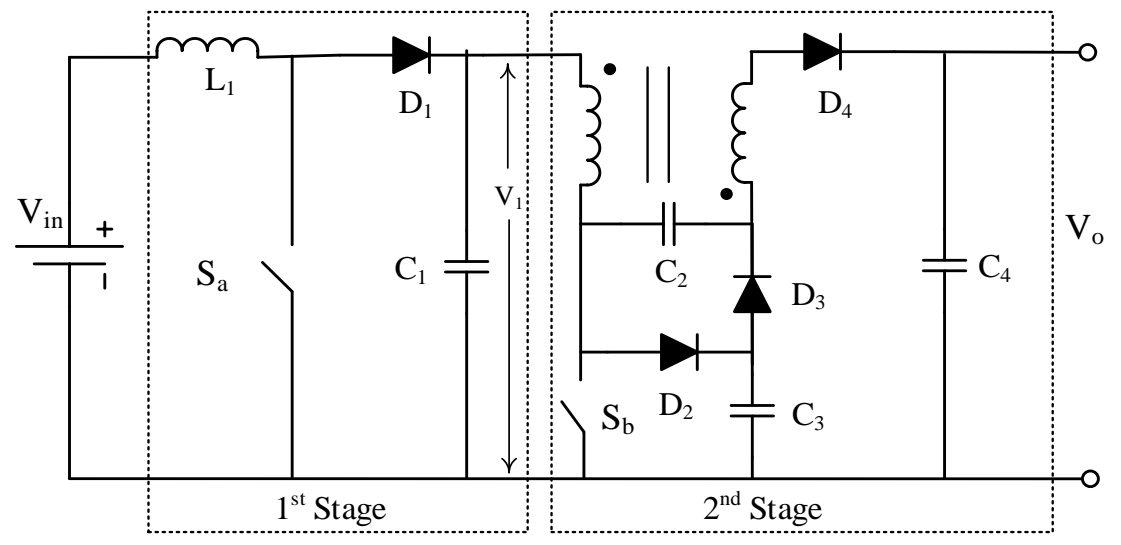

Figure 2. Proposed DC-DC converter.
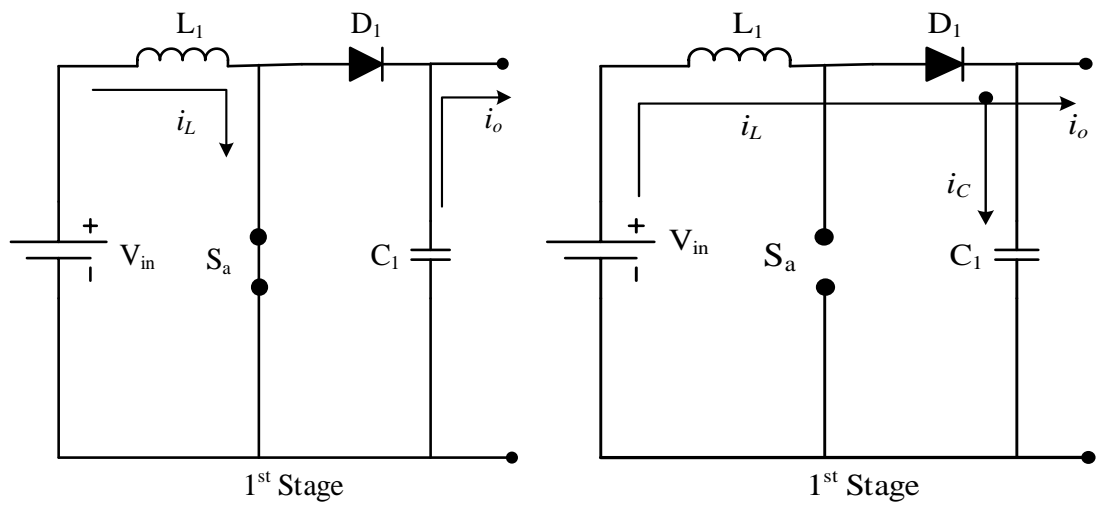

Figure 3. Topologies of first stage (a) $S_{a}$ is on (b) $S_{a}$ is off.

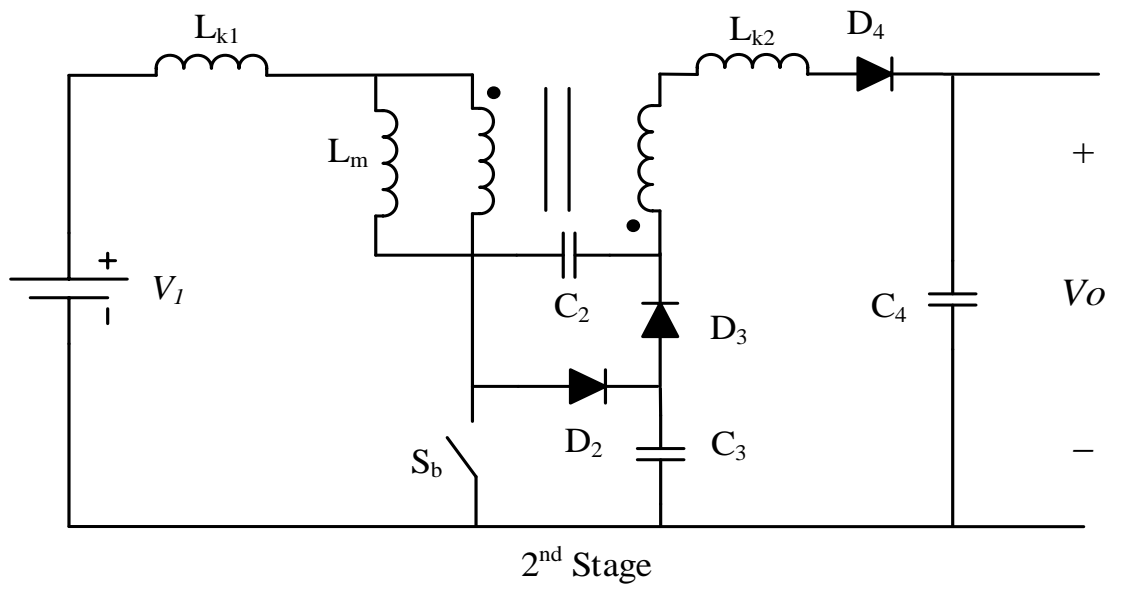

Figure 4. Second Stage of proposed converter.

second stage are shown in Figure 5. This stage as shown in Figure 6 can be analyzed in four operating modes.

Mode 1: The switch $S_{b}$ is initially turned on as shown in Figure 6(a). $D_{2}$ becomes reverse biased and the applied voltage causes the current on primary side to increase. In this mode, the current flowing through secondary winding is zero and there is increase in energy on the primary side. 


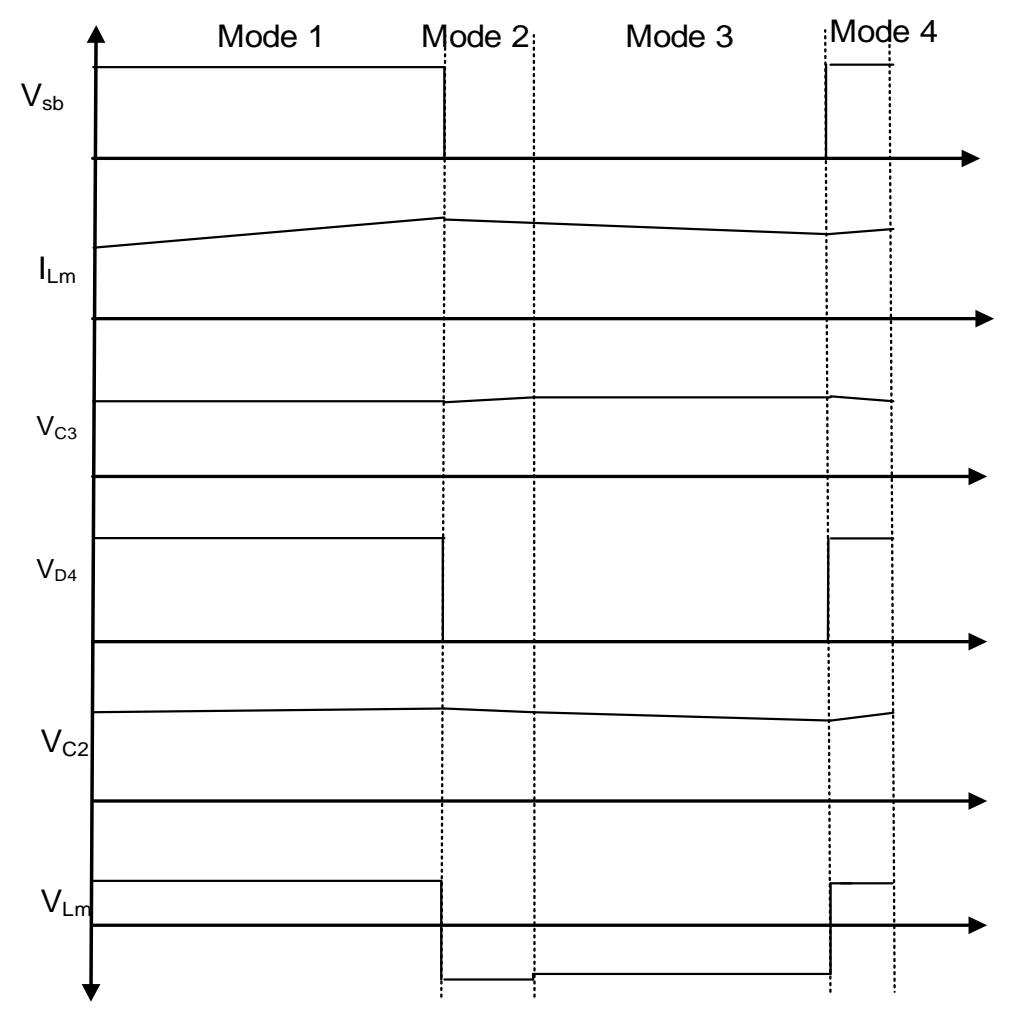

Figure 5. Steady state waveforms of the second stage.

Mode 2: In second mode, switch $S_{b}$ is turned off and diode $D_{2}$ is forward biased which charges capacitor $C_{3}$. The secondary winding is also receiving some of primary current via capacitor $C_{2}$ during this mode. The energy in magnetizing inductance decreases and there is increase in secondary current. Diode $D_{3}$ remains in off condition. Capacitor $C_{3}$ becomes charged at the end of this mode.

Mode 3: In this mode, switch $S_{b}$ remains off and $D_{2}$ becomes reverse biased. Primary, secondary windings and capacitor $C_{2}$ are series connected across the source. This allows the direct transfer of energy to the output from capacitor $C_{2}$, coupled inductor and source.

Mode 4: The switch $S_{b}$ is turned on and current on the primary side starts increasing there by storing energy in magnetizing inductance. Diode $D_{3}$ becomes forward biased and capacitor $C_{2}$ is charged by capacitor $C_{3}$. The current on secondary winding decays to zero and $D_{4}$ becomes reverse biased. The voltage across $C_{3}$ becomes equal to the voltage across $C_{3}$ causing diode $D_{3}$ to become reverse biased at the end of forth mode and the circuit proceeds to its initial condition.

Some assumptions are made for the derivation of voltage conversion ratio. The coupling co-efficient of coupled inductor is unity and the diodes are ideal. Let $V_{L m}, V_{L 2}, V_{1}$ and $V_{o}$ represent the voltages across magnetizing inductance, secondary winding, input and output of second stage respectively. $d_{2}$ is the duty ratio of second stage.

During on and off modes the inductor $L_{m}$ voltage is respectively given by: 


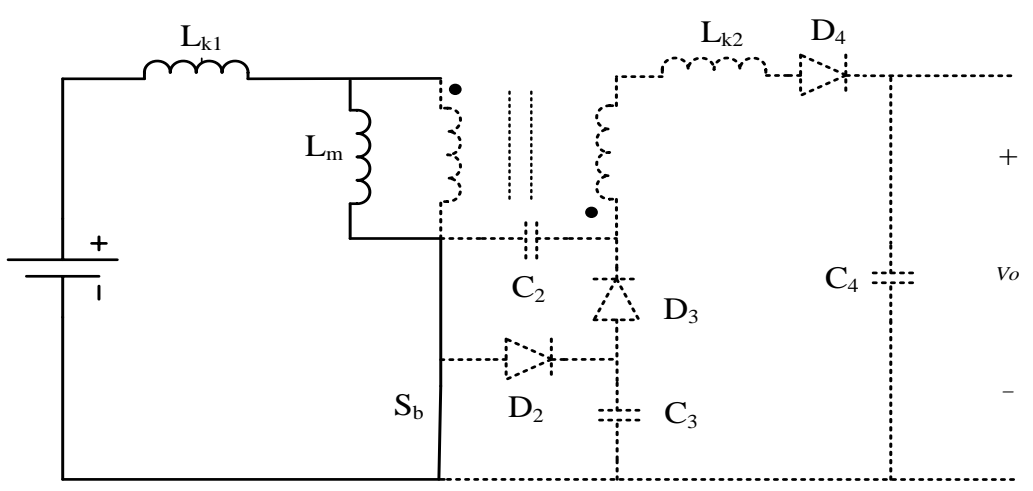

(a)

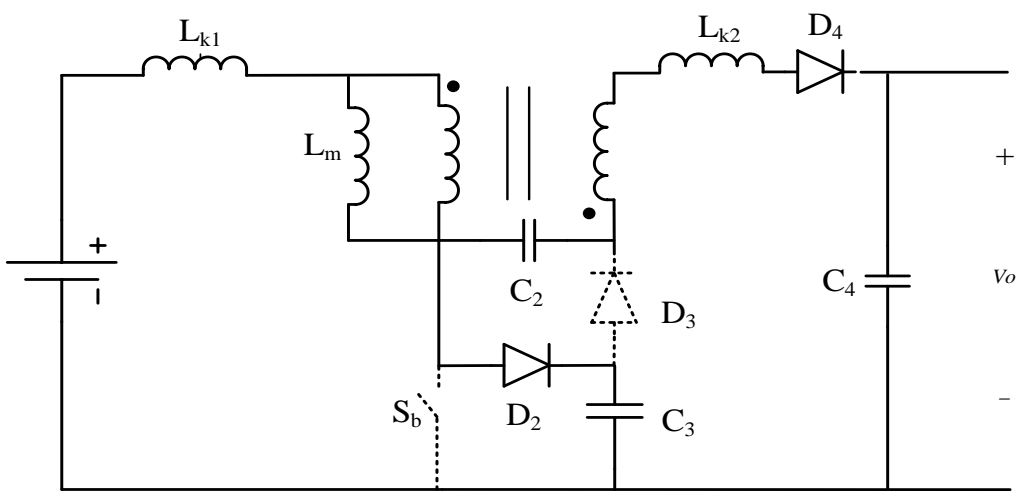

(b)

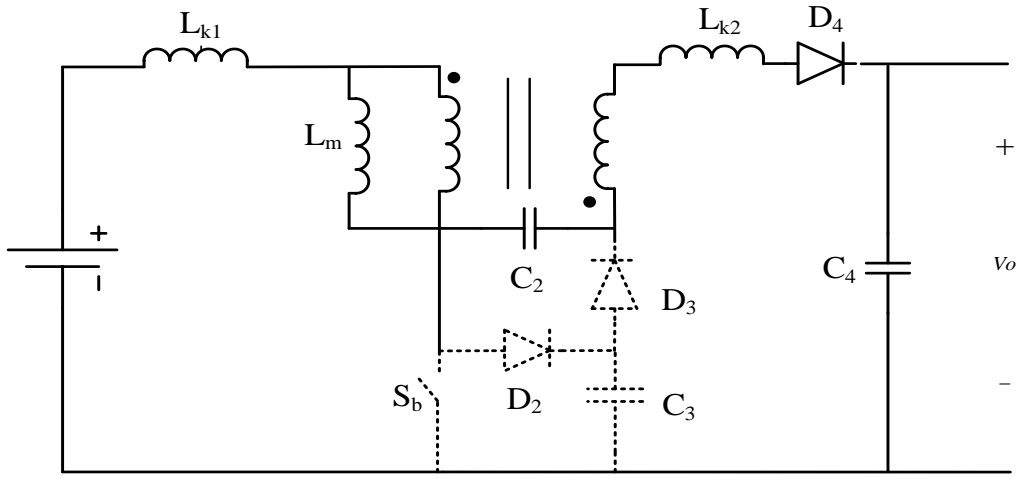

(c)

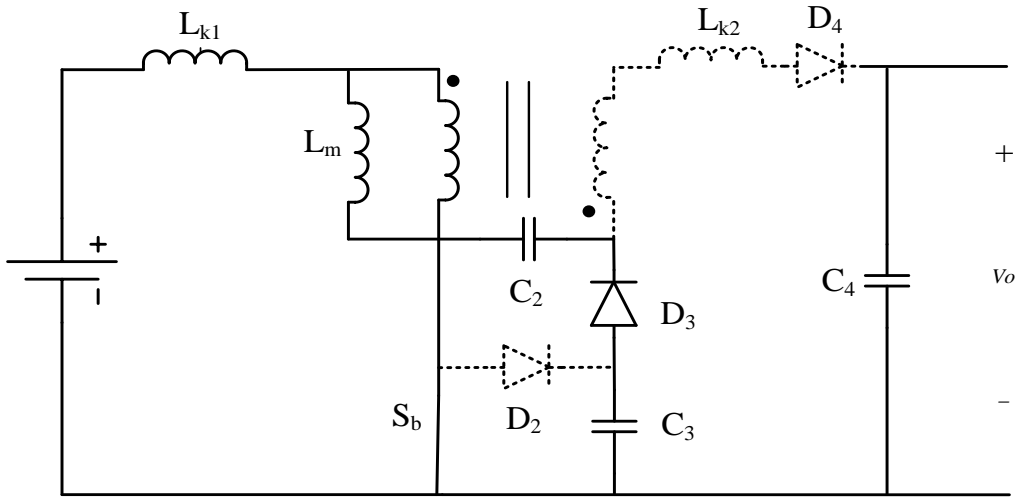

(d)

Figure 6. Topologies of second stage (a) Mode 1; (b) Mode 2; (c) Mode 3; (d) Mode 4. 


$$
\begin{gathered}
V_{L m}=V_{1} \\
V_{L m}=-\frac{V_{L 2}}{n}
\end{gathered}
$$

Application of inductor volt-second balance to Equation (2) and Equation (3) yields:

$$
\begin{gathered}
\left\langle V_{L m}\right\rangle=d_{2} V_{1}+d_{2}^{\prime}\left(-\frac{V_{L 2}}{n}\right)=0 \\
V_{L 2}=\frac{n d_{2} V_{1}}{d_{2}^{\prime}}
\end{gathered}
$$

Generally the relation between primary and secondary voltages is given the following equation:

$$
V_{L 2}=n V_{L m}
$$

The inductor $L_{m}$ voltage can be written from Equation (5) in the following form:

$$
V_{L m}=\frac{d_{2} V_{1}}{d_{2}^{\prime}}
$$

During Mode 2, the voltage across capacitor $C_{3}$ is given by the following equation:

$$
V_{C 3}=V_{1}+V_{L m}
$$

Substitution of Equation (6) into Equation (7) leads to the following equation:

$$
V_{C 3}=V_{1} \frac{1}{d_{2}^{\prime}}
$$

As capacitor $C_{2}$ is charged by capacitor $C_{3}$ and at the end of mode 4, $V_{C 2}=V_{C 3}$ so

$$
V_{C 2}=V_{C 3}=V_{1} \frac{1}{d_{2}^{\prime}}
$$

During Mode 3, apply KVL

$$
\begin{gathered}
V_{o}=V_{1}+V_{L m}+V_{c 2}+V_{L 2} \\
V_{o}=V_{1}+\frac{d_{2} V_{1}}{d_{2}^{\prime}}+\frac{V_{1}}{d_{2}^{\prime}}+\frac{n d_{2} V_{1}}{d_{2}^{\prime}} \\
\frac{V_{o}}{V_{1}}=\frac{2+n d_{2}}{d_{2}^{\prime}}
\end{gathered}
$$

This is the voltage gain of second stage and the voltage conversion ratio of proposed topology is obtained by the product of voltage gains of both the stages i.e.; the product of Equation (1) and Equation (10) yields:

$$
\frac{V_{o}}{V_{\text {in }}}=\frac{2+n d_{2}}{\left(1-d_{2}\right)\left(1-d_{1}\right)}
$$

Equation (11) is used to find the voltage conversion ratio of the proposed DC-DC converter. This equation illustrates that for a selected value of turn's ra- 
tio $n$, the required DC link voltage can be achieved at lower values of duty ratios.

\section{Grid Connected Inverter}

In order to synchronize the phase and frequency of inverter voltage with the grid, a signal is taken as reference from grid voltage. This feedback signal is converted into square wave in a comparator as shown in Figure 7. The positive and negative half cycles of the grid voltage appear as high and low voltage respectively at the output of the comparator. The rising and falling edges of this wave correspond to the start of positive and negative half cycle of grid sine wave respectively. The square wave actually determines the phase and frequency of the output of H-bridge inverter. The comparison of sinusoidal PWM signal for half of the period $(10 \mathrm{~ms})$ with same square wave generates gate drive signals for one pair of switches $\left(S_{1}, S_{4}\right)$. Similarly the comparison of sinusoidal PWM signal with inverted square wave for half of the period generates gate drive signals for the other pair of switches $\left(S_{2}, S_{3}\right)$. The transition from low to high in square will make switches $S_{1}$ and $S_{4}$ to turn on and $S_{2}$ and $S_{3}$ to turn off. Accordingly, the inverter voltage changes its polarity at exactly the same time as the grid voltage. Any shift in grid voltage is followed by the square wave generated accordingly. The same shift is adopted by the gate drive signals and hence the same shift occurs in the output voltage of inverter making it in phase with connected grid.

The inverter in this design operates at constant modulation index $(m)$ and the magnitude of grid voltage and its output voltage should be identical. This is accomplished by changing the duty ratio of DC-DC converter switches $\left(S_{a}, S_{b}\right)$ by a $\mu$-controller. The grid voltage is stepped down by a simple voltage divider circuit and a measured value is given to the $\mu$-controller which reads the input voltage $\left(V_{i n}\right)$ of converter and the voltage of grid $\left(V_{a c}\right)$. The $\mu$-controller calculates the desired output voltage $\left(V_{o}\right)$ of DC-DC converter using the grid voltage by the equation [13].

$$
V_{o}=\frac{V_{a c}}{0.707 \mathrm{~m}}
$$

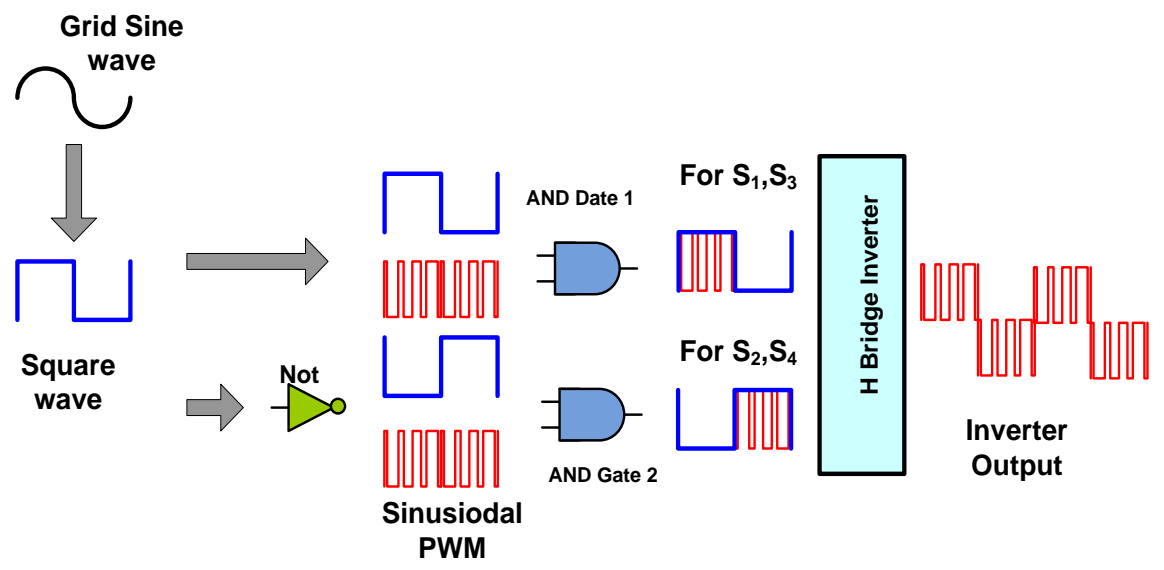

Figure 7. Frequency and phase synchronization. 
Equation (11) is used to compute the duty ratio (d). $T_{\text {on }}$ and $T_{\text {off }}$ are computed from the duty ratio. The frequency of switching signal is taken to be $20 \mathrm{KHz}$ and two timers are used to produce switching signals of this selected frequency and duty ratio for the operation of DC-DC converter.

\section{Simulation Results}

The system specifications and its design parameters are given in Table 1. The proposed topology has been validated by performing its simulation. The results demonstrate a good accordance with the analysis. Figure 8 shows the required voltage of $350 \mathrm{~V}$ is achieved at considerable low duty ratio and the output is almost ripples free. The converter has been simulated for the lowest value of input voltage, $V_{i n}=30 \mathrm{~V}$, still it operates excellently to give the required voltage at low value of $\sim 0.45$. Figure 8 also demonstrates that the proposed converter has less voltage stresses across the switches. The switch $S_{a}$ has less voltage stress which is about $60 \mathrm{~V}$. The voltage stress across $S_{b}$ is less than $110 \mathrm{~V}$ which is far less than

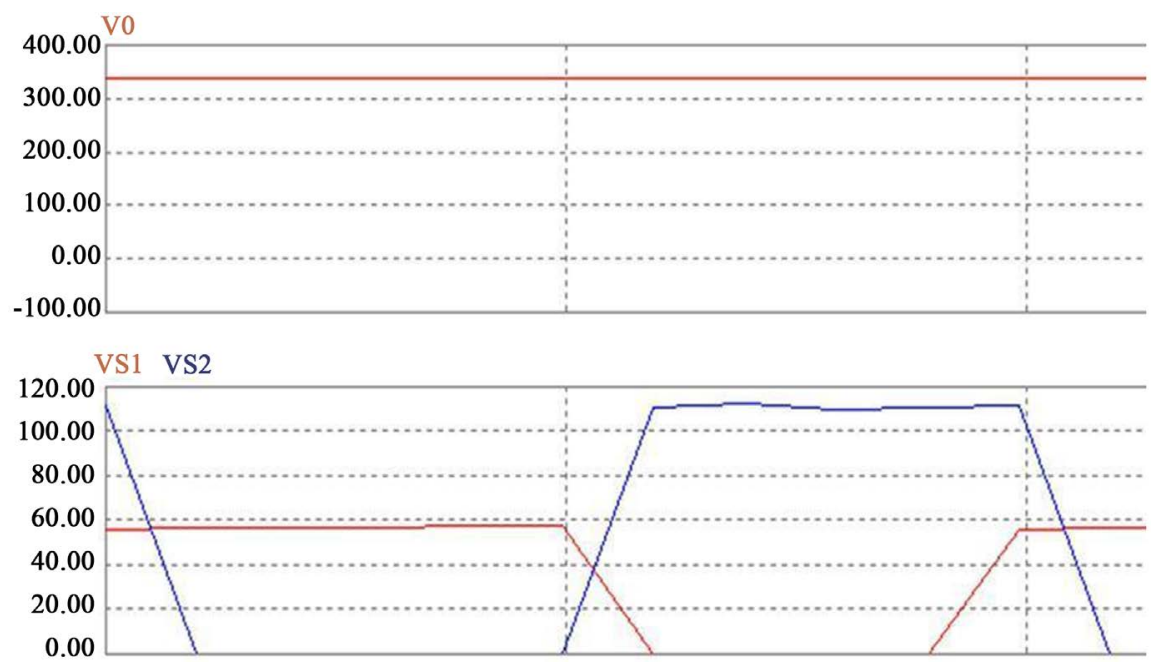

Figure 8. DC-DC converter output.

Table 1. System specifications and parameters.

\begin{tabular}{ccc}
\hline Specification and parameters & Symbols & Values \\
\hline Input voltage & $V_{i n}$ & $30-60 \mathrm{~V}_{\mathrm{DC}}$ \\
DC link voltage & $V_{d}$ & $350 \mathrm{~V}$ \\
Output voltage & $V_{a c}$ & $220 \mathrm{~V}$ \\
Frequency & $f$ & $50 \mathrm{~Hz}$ \\
Power capacity & $P$ & $500 \mathrm{watt}$ \\
Boost stage inductance & $L_{I}$ & $31 \mu \mathrm{H}$ \\
Magnetizing inductance & $L_{m}$ & $188 \mu \mathrm{H}$ \\
Filter inductance & $L$ & $2.5 \mathrm{mH}$ \\
Filter capacitance & $C$ & $4 \mu \mathrm{F}$ \\
\hline
\end{tabular}


the output voltage $(350 \mathrm{~V})$. These less stresses allow the selection of switches in the design procedure to have low voltage ratings. This lowers the cost of the proposed PV system. Comparison has been made been made in Figure 9 among the proposed topology, simple boost, flyback, cascaded boost flyback and another high voltage gain converter presented in [14]. This comparison has been made for the same input voltage. The voltage conversion ratio of cascaded boost flyback convert can be increased by selecting the higher value of turn's ratio. But this will increase the size of the system. Figure 9 shows that the voltage conversion ratio $(M)$ of proposed topology is very high in comparison with the other converters.

The required DC voltage can be achieved at low duty ratio of $\sim 0.4$ in the proposed converter. The lower value of duty ratio decreases the conduction losses and hence improves the efficiency of the proposed system to some extent. The $\mathrm{H}$-bridge inverter has been also simulated. Figure 10 shows the simulated results of inverter's output. The output of inverter is square wave and not suitable for most of the applications, so a low pass filter has been designed and simulated. This filter eliminates most of the ripples from the inverter's output. The output of low pass LC filter is also shown in Figure 11. This simulation result shows that the output voltage is almost sinusoidal having low ripples. This can be used for most of the electrical loads. This output is applied to grid to meet the present day demand of energy.

\section{Conclusion}

This paper proposes the grid-connected photovoltaic system with a proposed topology of DC-DC converter. The converter with a high voltage conversion ratio can easily boost up the lower PV voltage to the required DC voltage at low duty ratio. As the gain is high, this allows the parallel operation of PV modules and also eradicates the need of power transformer to achieve the required grid

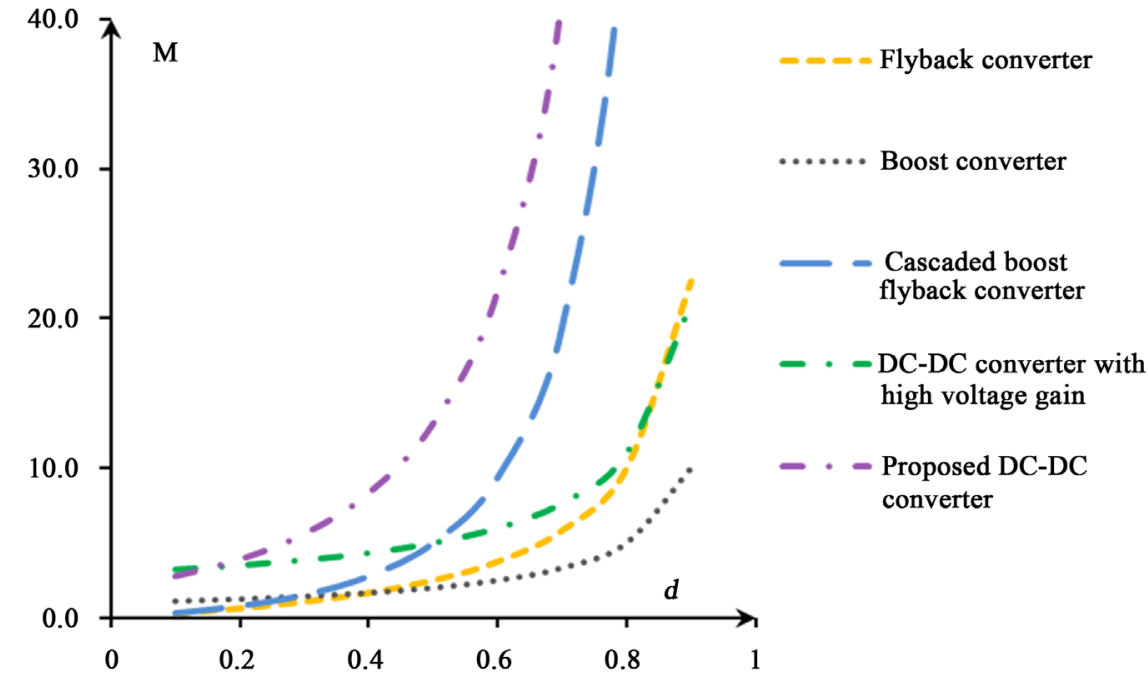

Figure 9. Comparison of DC-DC converter with other topologies. 


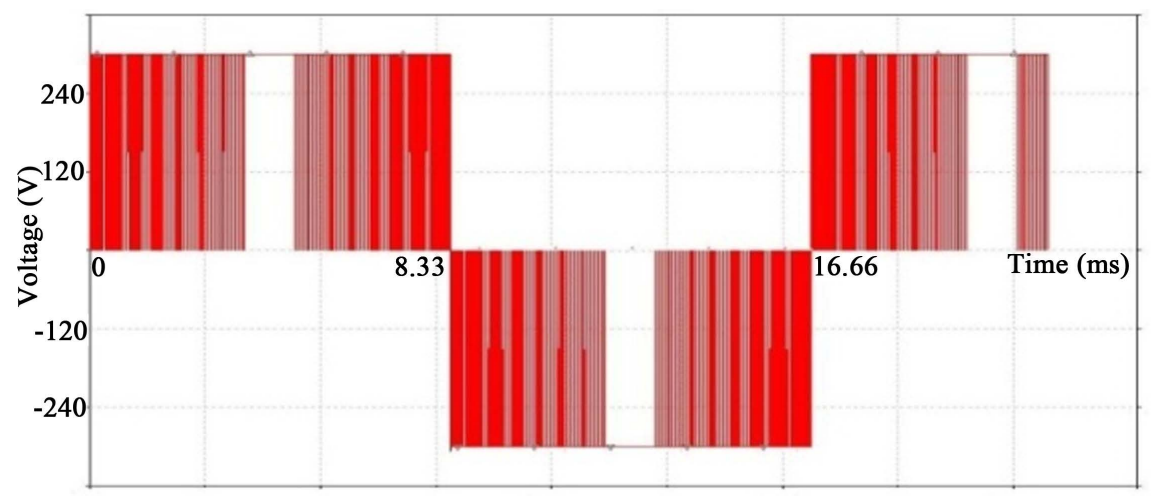

Figure10. Inverter output voltage.

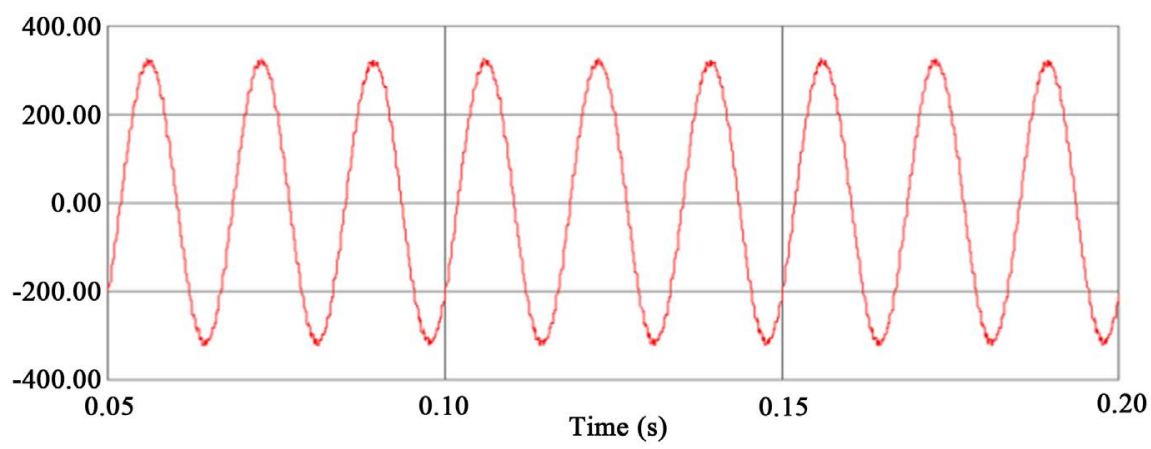

Figure 11. Inverter output using filter.

voltage. This results in high efficiency and reduced size of this system. The converter has low voltage stresses across the switches with decreased cost of the system. The system is beneficial in terms of unit saving as it can meet the demand of load. It may be implemented for a three-phase system.

\section{References}

[1] Chen, Y. and Smedley, K.M. (2004) A Cost-Effective Single-Stage Inverter with Maximum Power Point Tracking. IEEE Transactions on Power Electronics, 19, 12891294. https://doi.org/10.1109/TPEL.2004.833458

[2] Andersen, G.K., Klumpner, C., Kjaer, S.B. and Blaabjerg, F. (2002) A New Green Power Inverter for Fuel Cells. Power Electronics Specialists Conference, 2, 727-733. https://doi.org/10.1109/psec.2002.1022540

[3] Mohan, N. and Undeland, T.M. (2007) Power Electronics: Converters, Applications, and Design. John Wiley \& Sons, Hoboken.

[4] Maksimovic, D. and Cuk, S. (1991) Switching Converters with Wide DC Conversion Range. IEEE Transactions on Power Electronics, 6, 151-157.

https://doi.org/10.1109/63.65013

[5] Maksimovic, D. (1989) Synthesis of PWM and Quasi-Resonant DC-DC Power Converters. Doctoral Dissertation, California Institute of Technology, California.

[6] Calais, M., Myrzik, J., Spooner, T. and Agelidis, V.G. (2002) Inverters for SinglePhase Grid Connected Photovoltaic Systems: An Overview. Power Electronics Specialists Conference PESC, 4, 1995-2000.

[7] Kjaer, S.B., Pedersen, J.K. and Blaabjerg, F. (2002) Power Inverter Topologies for 
Photovoltaic Modules: A Review. Industry Applications Conference, 2, 782-788. https://doi.org/10.1109/ias.2002.1042648

[8] Kazmierkowski, M.P. and Malesani, L. (1998) Current Control Techniques for Three-Phase Voltage-Source PWM Converters: A Survey. IEEE Transactions on Industrial Electronics, 45, 691-703. https://doi.org/10.1109/41.720325

[9] Kojabadi, H.M., Yu, B., Gadoura, I.A., Chang, L. and Ghribi, M. (2006) A Novel DSP-Based Current-Controlled PWM Strategy for Single Phase Grid Connected Inverters. IEEE Transaction Power Electronics, 21, 985-993. https://doi.org/10.1109/TPEL.2006.876851

[10] Kjaer, S.B., Pedersen, J.K. and Blaabjerg, F. (2005) A Review of Single-Phase GridConnected Inverters for Photovoltaic Modules. IEEE Transactions on Industry Applications, 41, 1292-1306. https://doi.org/10.1109/TIA.2005.853371

[11] Barbosa, P.G., Rolim, L.G.B., Watanabe, E.H. and Hanitsch, R. (1998) Control Strategy for Grid-Connected DC-AC Converters with Load Power Factor Correction. IEE Proceedings-Generation, Transmission and Distribution, 145, 487-492. https://doi.org/10.1049/ip-gtd:19982174

[12] Jung, H.Y., Ji, Y.H., Won, C.Y., Song, D.Y. and Kim, J.W. (2010) Improved GridSynchronization Technique Based on Adaptive Notch Filter. 2010 International Power Electronics Conference (IPEC), Sapporo, 21-24 June 2010, 1494-1498. https://doi.org/10.1109/IPEC.2010.5544516

[13] Singh, M.D. (2008). Power Electronics. Tata McGraw-Hill Education, Pennsylvania Plaza.

[14] Yang, L.S., Liang, T.J. and Chen, J.F. (2009) Transformerless DC-DC Converters with High Step-Up Voltage Gain. IEEE Transactions on Industrial Electronics, 56, 3144-3152. https://doi.org/10.1109/TIE.2009.2022512

\section{Submit or recommend next manuscript to SCIRP and we will provide best service for you:}

Accepting pre-submission inquiries through Email, Facebook, LinkedIn, Twitter, etc. A wide selection of journals (inclusive of 9 subjects, more than 200 journals)

Providing 24-hour high-quality service

User-friendly online submission system

Fair and swift peer-review system

Efficient typesetting and proofreading procedure

Display of the result of downloads and visits, as well as the number of cited articles

Maximum dissemination of your research work

Submit your manuscript at: http://papersubmission.scirp.org/

Or contact jpee@scirp.org 